\title{
O Brasil e a Revolução Educacional
}

JACK SOIFER

Técnico em Telepedagogia do Centro Nacional de Recursos Humanos, do IPEA - Ministério do Planejamento e Coordenação-Geral

Há quatro problemas básicos na educação brasileira: quantidade, qualidade, tempo e infra-estrutura rural.

O Brasil deverá atender a 20 milhões de crianças e jovens em 1975. Isto custará ao país quase 2 bilhöes de dólares anualmente, sendo a metade destinada aos salários dos professôres primários e secundários.

Além do sistema escolar deveremos investir em educação suplementar, auxiliando adultos que hoje sentem necessidade de saber mais. São prioritários a alfabetização funcional, a recuperação do ensino primário e, principalmente, 0 treinamento profissional básico, condição essencial à introdução de tecnologia contemporânea nos setores primário (agropecuária, pesca, etc.), e terciário (comércio, transporte, serviços, etc.), da economia, onde ainda geralmente prevalecem técnicas antiquadas.

Além do problema quantitativo, existe o qualitativo talvez ainda mais dificil. Quarenta $e$ dois por cento dos professôres primários não são diplomados; o currículo está longe da rea- lidade dos alunos; as condições de estudo das crianças são geralmente impróprias. Estes fatôres incidem negativamente no pouco interêsse inicial, levando-os à repetência e a deixar a escola. Na primeira série estão quase metade dos alunos do primário. De acôrdo com os dados do Serviço de Estatística de Educação e Cultura, dos 5,2 milhöes de matrículas na primeira série primária em 1966, 1,9 matriculouse na segunda em $67,1,8$ abandonou os estudos e 1,5 repetiu o ano. Dos 5,2 milhões em 1966, estimamos que no máximo 1 milhão se matriculou no ginásio em 1970 (veja gráfico).

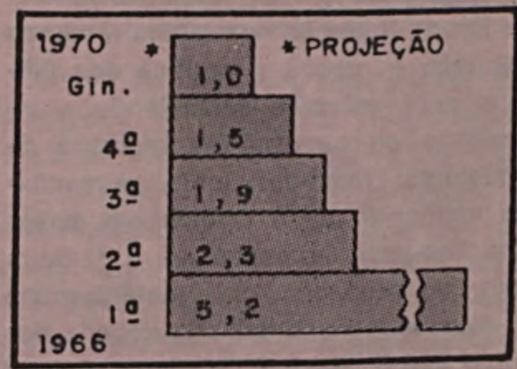

Fluxo de alunos na escola primária (EM MILHŌES DE ALUNOS) 
O terceiro problema básico da educação brasileira é o tempo. Das 200 mil professôras primárias ainda não diplomadas formam-se anualmente 5 mil. A não ser que métodos diferentes sejam usados, precisaremos de duas gerações só para diplomar êste grande contingente. Enquanto isto as metodologias educacionais estarão mudando e as crianças estarão, até a devida capacitação das professôras, recebendo um ensino inadequado e desestimulador.

Cabe notar que a falta de professôres é paradoxal, pois uma elevada percentagem das que se formam não desempenha suas funções, e, enquanto há falta de normalistas no interior, existe excesso nas capitais.

Finalmente, o quarto problema: a falta de condições das áreas rurais, especialmente aquelas de difícil acesso, impossibilita a oferta de ensino fundamental condizente a todo o nosso país, agravando os três problemas antes citados e por esta razão tornando-se um problema à parte.

A inexistência de profissionais capacitados condiciona o aproveitamento máximo de novos métodos de produção. E aí está, a meu ver, o ponto de estrangulamento do desenvolvimento no Brasil. Pois não nos faltam recursos naturais; e graças à política dos últimos anos estamos acumulando $e$ investindo os necessários recursos financeiros; resta-nos, pois, aproveitar da melhor forma e investir em massa nos recursos humanos - o terceiro fator de produção, cuja matéria-prima é abundante no Brasil. Na década dos 70 o Brasil terá de "queimar etapas" de técnicas de produção, sob pena de não mais atingir os países desenvolvi- dos, cuja avançada tecnológica tende a aumentar a distância dos paises em desenvolvimento. Nesses 10 anos teremos que formar e atualizar a mão-deobra necessária ao país, assim como preparar o indivíduo, centro de nossas atenções, para poder dominar o mundo complexo e tecnocrático que o cercará.

Os quatro problemas acima citados nos obrigam a pensar em novas tecnologias educacionais, especialmente as de comunicação em massa, para, dinamizando a educação, melhor desenvolver o Brasil.

No Brasil, até o momento, não foram usadas, sistemàticamente, novas tecnologias educacionais, embora tenhamos sido um dos primeiros países a utilizar - rádio, temporàriamente, para fins educativos (em 1929). Sòmente em princípios da década passada é que o rádio teve atuação real, através dos trabalhos do Movimento de Educação de Base (MEB), sob a orientação da Conferência Nacional dos Bispos do Brasil, trabalho que foi premiado pela UNESCO em 1968.

\section{O QUE É TECNOLOGIA EDUCACIONAL}

Tecnologia educacional pode ser interpretada como combinações de meios e métodos para utilização eficiente dos processos psicopedagógicos, a fim de permitir aos alunos, com o mínimo de custo e tempo, atingir objetivos preestabelecidos e que possam ser medidos.

Entre os meios citamos:

- humanos (professor);

- auditivos (toca-discos e gravadores, laboratórios de línguas, rádio);

- visuais (quadro-negro e cartazes, projetores de slides etc.); 
- audiovisuais (cinema, TV, etc.);

- impressos (livros, correspondência, periódicos etc.);

- mecânicos e eletrônicos (máquina de ensino, computador).

Entre os métodos, o de maior destaque é o da instrução programada.

COMO CRIAR PROGRAMA EDUCACIONAL?

Normalmente um sistema de transformação começa pela formulação dos objetivos a serem atingidos. Estabelecidos os objetivos gerais (no sistema escolar, currículos; na preparação profissional, descrição de tarefas) especificam-se os detalhes, para que se possam mais tarde medir os resultados da aprendizagem e compará-los aos objetivos. Depois cria-se um sistema de provas e testes para avaliação, necessárla para o indivíduo (normas de aprovação) e para aprimoramento de programa (o que não foi aprendido? Por quê?).

Temos de estudar os alunos para conhecer ou estimar seus conhecimentos prévios, formas gerais de comportamento; tipo de linguagem, etc. (que é diferente no campo, nas cidades médias e nas grandes metrópoles). Precisamos também conhecer o meio-ambiente, para escolher exercicios que interessem aos alunos e para bem dosar as informações transmitidas, a fim de garantir sua assimilação total no minimo de tempo. $O$ estudo da situação de aprendizagem também nos permite avaliar a eficiência dos diversos meios de comunicação e escolher a estratégia de ensino.

De posse dêsses dados e baseados nos conhecimentos de psicologia da aprendizagem construímos um programa, ou seja, compomos um complexo de informações, exercícios, repetiçōes etc.

Os meios de comunicação dêste programa podem variar, desde o professor - que pode seguir um roteiro mimeografado - até o computador combinado com TV. A escolha do meio ideal é baseada nas estimativas do custo de investimento e operação, dividido pela eficácia pedagógica (grau de aproveitamente $x$ quantidade de alunos) fornecida pela avaliação do mesmo tipo de programa ministrado por diferentes meios de comunicação.

Por exemplo, usando os métodos convencionais, diplomados 1 milhão de crianças no primário, a um custo anual de 300 milhões de dólares, ou seja, 300 dólares por aluno diplomado. Se usando combinação de professor-audiovisuais aumentarmos a diplomação anual para 2 milhões a um custo de, digamos, 500 milhões de dólares, 0 aluno diplomado custará 250 dólares. Portanto, só se justificarla a combinação professor-TV se o custo do aluno diplomado (pressupondo qualidade invariável) fôsse igual ou inferior a êsses 250 dólares.

Raciocínio semelhante $\delta$ aplicável a cada parte integrante de um curso.

Antes da produção em massa do programa, é necessário fazer testes práticos em amostras representativas dos alunos, seguidos de avaliação e reformulação. Esta etapa deve ser repetida até que, de preferência, $90 \%$ dos alunos respondam $90 \%$ dos exercícios corretamente. Mas para populações muito heterogêneas e para pequenos grupos aceita-se percentagem menor. 
Para que o programa seja bem utilizado devemos informar aos professôres ou monitores como obter o maior rendimento do material fornecido. Normalmente êles recebem um manual ou guia especial. Êles serão sempre os elementos-chave no processo de comunicação em massa, pois poderão auxiliar um aluno, caso êste encontre alguma dificuldade extra.

Para quem produz o material é essencial ter conhecimento das reações dos alunos, e portanto, a experiência dos professôres ou monitores deve ser continuamente relatada ao produtor. A isto se chama feedback.

Convém deixar claro que, com algumas exceções, os "programas de ensino" não podem substituir os professôres ou monitores. Substituem, isto sim, as tarefas rotineiras (dar e repetir informações) deixando-lhes as nobres (por ex. ensinar a raciocinar, desenvolver o relacionamento humano, sociabilizar) e mais tempo para o contato individual com cada aluno.

\section{A CONJUNTURA ATUAL}

A fim de coordenar atividades dispersas de TV e rádio educativos e introduzir um Sistema Avançado de Tecnologias Educacionais (SATE), foi criada uma Comissão Interministerial composta pelos titulares da Fazenda, Educação, Comunicações, Relações Exteriores, Planejamento e pelo presidente do Conselho Nacional de Pesquisas.

Com o objetivo de sugerir medidas e determinar estudos, a Comissão tem um Grupo Técnico de Coordenação, formado por representantes da Fundação Centro Brasileiro de TV-Educativa (FCBTVE), Conselho Nacional de Tele- comunicações (CONTEL), Conselho Federal de Educação (CFE), Comissão Nacional de Atividades Espacia is (CNAE), Ministério das Relações Exteriores (MRE) e Instituto de Planejamento Econômico e Social (IPEA), sendo o último o coordenador do Grupo.

A Comissão solicitou sugestões imediatas para normalizar o setor de televisão cultural, onde se gastam fortunas atualmente.

As estações em funcionamento atingem apenas uma pequena camada da população e, normalmente, exatamente aquela que já tem o melhor nível educacional.

Estima-se que $\mathrm{Cr} \$ 28$ milhões serão gastos êste ano com a TV cultural e educativa no Brasil, sendo seus resultados mais criticados do que elogiados pelos técnicos.

Não podemos negar que a TV Educativa atualmente é cara, principalmente devido à nossa incapacidade de obter, a curto prazo, o seu máximo rendimento pedagógico.

\section{RADIOEDUCATIVO}

O Govêrno Médici dá prioridade ao desenvolvimento rural e nessas áreas - rádio atinge hoje muito mais que a TV. Lá está também o maior número de professôres leigos e, presume-se, a maior concentração de alunos na 1 ạ série primária.

Por isso seria conveniente iniciar imediatamente projetos de radioeducativo em zonas rurais de alguns Estados, aprimorando o conhecimento já adquirido neste setor. Os objetivos prioritários seriam o descongestionamento da 1 ạ série, paralelamente à melhora qualitativa do professorado e curtos $\theta$ 
intensivos programas de treinamento para melhoria da produtividade agropecuária e educação assistemática, do tipo "um programa - um objetivo", onde noçőes de higiene, cooperação, autodesenvolvimento, civismo etc. seriam ministradas.

Além de poder avaliar de forma condizente os experimentos já iniciados por diversos órgãos, seguindo mesmo filosofias diferentes, estariamos criando uma infra-estrutura de radiopostos, monitores, supervisores etc., que poderiam ser aproveitados quando da introdução da TV Educativa.

A cooperação de entidades como as ACAR (Associações de Crédito e Assistência Rural), do Ministério da Agricultura, Superintendências de Desenvolvimento, do Ministério do Interior, Departamento Nacional de Endemias Rurais, do Ministério da Saúde, Departamentos de Estradas de Rodagem, dos Estados e outros órgãos federais, estaduais ou municipais que atuem nas áreas programadas é indispensável.

Estima-se que mals de $80 \%$ da população rural brasileira ( $40 \%$ do total) são atingidos pelo rádio. Com a regulamentação das cinco horas obrigatórias, 900 emissoras de rádio, bem mais da metade no interior, deverão transmitir 4.500 horas por semana de programação educativa. Ainda não temos capacidade de produzir, seguindo as boas normas antes enumeradas, o fabuloso número de horas disponiveis mesmo que multas estações usem o mesmo programa. Por isto talvez fôsse conveniente nos concentrarmos inicialmente em utilizar para educação as rádios do interior, deixando que as emissoras das megalópoles, como Rio e São Paulo, onde já existe uma vasta e relativamente eficiente rêde escolar, transmitam apenas cultura nesta primeira etapa. Estaríamos assim concentrando nossos poucos recursos humanos capacitados neste onde êles são mais necessários.

$O$ reduzido custo de produção de radioeducativo, comparado com TV. E, a enorme oferta de tempo da rêde de rádio comercial que atinge $o$ interior, a experiência já adquirida neste setor no Brasil e, especialmente, a urgente necessidade de se somarem esforços para a importante tarefa de desenvolver as áreas rurais nos faz acreditar ser o radioeducativo no mínimo tão prioritário quanto a TV.

"Jornal do Brasil", 16-8-70 